Terbit online pada laman web jurnal : http://e-journal.sastra-unes.com/index.php/JIPS

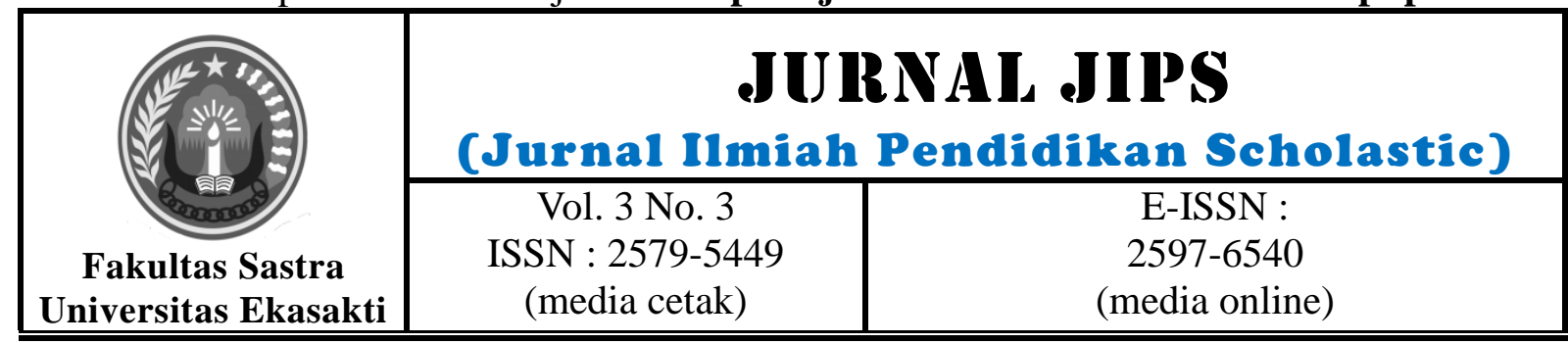

\title{
EFEKTIFITAS MODEL PEMBELAJARAN KOOPERATIF TIPE SCRAMBLE DALAM PEMBELAJARAN MATEMATIKA
}

\author{
Iltavia, Nurhasnah \\ Pendidikan Matematika FKIP UMSB \\ ilta.rangbuki@gmail.com
}

\begin{abstract}
The problem formulation in this study is 1). How is the teacher's activity in the application of a scramble type cooperative learning model on Mathematics learning in class XI SMK Cendana Padangpanjang 2017/2018 Academic Year? 2). How is the activity of students in the application of scramble type cooperative learning models in mathematics learning in class XI SMK Cendana Padangpanjang class year 2017/2018, 3). Are students' mathematics learning outcomes using a scramble type cooperative model on effective mathematics learning to improve mathematics learning outcomes in the cognitive domain? To test the validity of the hypothesis the pretest and posttest values were analyzed using the $t$-test. Obtained $t_{\text {hitung }}=6,99>1.71=t_{(0,05 ; 20)}$ then $H_{0}$ rejected and $H_{1}$ be accepted. This has the effect of increasing the percentage of good completeness as much as $75 \%$ of the mathematics learning outcomes. From the results of data analysis it can be concluded that by applying the Scramble Type Cooperative learning model has a good effect on students' mathematics learning outcomes in class XI TKJ SMK Cendana Padangpanjang.
\end{abstract}

Keywords: Effectiveness, Scramble Types, Cooperative Learning Models

(C) 2019Jurnal JIPS

\begin{abstract}
Abstrak
Rumusan masalah dalam penelitian ini adalah 1). Bagaimana aktivitas guru dalam penerapan model pembelajaran kooperatif tipe scramble pada pembelajaran Matematika di kelas XI SMK Cendana Padangpanjang 2017/2018 Tahun Akademik? 2). Bagaimana aktivitas siswa dalam penerapan model pembelajaran kooperatif tipe scramble dalam pembelajaran matematika di kelas XI SMK Cendana Padangpanjang kelas tahun 2017/2018, 3). Apakah hasil belajar matematika siswa menggunakan model kooperatif tipe scramble pada pembelajaran matematika yang efektif untuk meningkatkan hasil belajar matematika dalam ranah kognitif? Untuk menguji validitas hipotesis, nilai pretest dan posttest dianalisis menggunakan uji-t. Diperoleh $t_{\text {hitung }}=6,99>1.71=t_{(0,05 ; 20)}$ maka $H_{0}$ ditolak dan $H_{1}$ diterima. Ini memiliki efek meningkatkan persentase ketuntasan yang baik sebanyak $75 \%$ dari hasil belajar matematika. Dari hasil analisis data dapat disimpulkan bahwa dengan menerapkan model pembelajaran Cooperative Type Scramble memiliki pengaruh yang baik terhadap hasil belajar matematika siswa di kelas XI TKJ SMK Cendana Padangpanjang
\end{abstract}

Keywords: Efektivitas, Tipe Scramble, Model Pembelajaran Kooperatif

Jurnal JIPS (Jurnal Ilmiah Pendidikan Scholastic ) Vol. 3 No. 3 (2019) ISSN : 2579-5449

This work is licensed under a Creative Commons Attribution-NonCommercial 4.0 International License. 


\section{INTRODUCTION}

Pendidikan memegang peranan yang sangat penting dalam kehidupan. Manusia sangat memerlukan pendidikan untuk memperoleh ilmu pengetahuan. Ilmu pengetahuan yang dimiliki oleh seseorang itu bisa mengantarkan orang yang bersangkutan kepada kesuksesan.

Pendidikan tidak hanya ada di bangku formal saja, tapi juga di bangku non formal. Pendidikan di bangku non formal diperoleh dari keluarga, lingkungan masyarakat dan alam. Selama siswa mengalami pendidikan non formal siswa bisa memperoleh banyak ilmu yang bisa berguna dalam kehidupannya. Pendidikan formal diperoleh siswa di sekolah, di lingkungan yang akan menciptakan sebuah generasi baru bagi bangsa, yaitu generasi yang berilmu pengetahuan. Pendidikan formal juga menyajikan berbagai ilmu pengetahuan dan matematika adalah salah satu ilmu pengetahuan atau mata pelajaran yang selalu hadir dalam pendidikan formal.

Matematika merupakan salah satu pelajaran yang sering dianggap sebagai mata pelajaran yang susuah untuk dimengerti. Banyak sekali siswa yang tidak suka dengan pelajaran matematika. Sering kali dijumpai bahkan ditemukan ketakutan siswa dalam mengerjakan soal matematika. Indikasinya dapat diliihat dari hasi belajar siswa yang kurang memuaskan. Selama ini umumnya siswa hanya bermodal menghafal rumus untuk menyelesaikan soal soal matemaika.

Matematika adalah ilmu tentang logika mengenai bentuk, susunan, besaran, dan konsep - konsep yang berhubungan satu dengan yang lainnya dengan jumlah yang banyak yang terbagai kedalam tiga bidang, yaitu aljabar, analisis dan geometri. Namun pembagian yang jelas sangatlah sukar untuk dibuat, sebab cabang - cabang itu semakin bercampur. Sebagai contoh, adanya pendapat yang mengatakan bahwa matematika itu timbul karena pikiran pikiran manusia yang berhubungan dengan ide, proses, dan penalaran yang terbagi menjadi empat wawasan yang luas, yaitu aritmatika, aljabar, geometri dan analisis dengan aritmatika mencakup teori bilangan dan statiska menurut
James dan James (dalam Suherman dkk, 2003 : 16).

Pengajaran matematika merupakan sarana penunjang untuk berbagai penunjang disiplin ilmu pengetahuan lainya, baik dalam ilmu pengetahuan alam maupun ilmu pengetahuan sosial. Pengalaman pertama siswa dalam mempelajari matematika umumnya akan menentukan sikap siswa terhadap matematika. siswa akan senang dan berminat mempelajari matematika apabila siswa mendapatkan kesan yang baik pada saat siswa mempelajari matematika untuk kalinya. Sebalikya, pengalaman pertama yang buruk atau siswa tidak senang dan merasa kesulitan terhadap matematika dan mempengaruhi motivasinya terhadap pembelajaran matematika. Hal ini tentu akan berpengaruh pada hasil belajar siswa terhadap mtematika. Oleh karena itu, rendahnya hasil belajar siswa terhadap matematika bukan semata - mata kesalahan siswa dan jika hasil belajar masih rendah, maka gejala yang akan muncul adalah para siswa akan terus - menerus akan mengalami kesulitan dalam mengepresikan pikiran dan perasaan secara lancar, kesulitan menyusun jalan pemecahan masalah yang tepat. Hal tersebut akan berdampak buruk pada hasil belajar siswa.

Namun pada kenyataannya tujuan pembelajaran matematika tersebut belum tercapai, dengan melihat data persentase nilai ujian harian kelas XI TKJ SMK Cendana Padangpanjang. Hal tersebut senada dengan masalah yang peneliti temui di SMK Cendana Padangpanjang.

Berdasarkan wawancara dan hasil observasi dengan guru matematika kelas XI SMK Cendana Padangpanjang, bahwa faktor yang mempengaruhi rendahnya hasil belajar matematika siswa diantaranya guru masih kurang berinofasi dengan model - model pembelajaran yang ada dan kurangnya variasi dalam pemberian soal, menyebabkan tingkat pemahaman siswa terhadap materi yang diajarkan masih kurang sehingga mempengaruhi hasil belajar siswa, Siswa tidak memperhatikan guru pada saat menerangkan pelajaran dan asik dengan kesibukanya masing-masing, guru masih 
memakai buku dari sekolah sebagai sumbernya, kurang aktifnya siswa dalam proses pembelajaran dengan model pembelajaran yang digunakan guru. Oleh karena itu sebagian besar siswa tidak memperhatikan saat pembelajaran matematika berlangsung dan asik dengan kesibukanya masing - masing sehingga tidak dapat menerima pembelajaran dengan baik, maka mempengaruhi hasil belajar siswa dan dapat dilihat dari hasil ujian harian siswa yang masih banyak di bawah KKM.

Rendahnya hasil belajar siswa terhadap pembelajaran suatu materi tertentu disebabkan kurangnya inovasi guru dalam model - model pembelajaran matematika. Komponen kompoen yang terkait dalam proses belajar diantaranya tujuan pengajaran, bahan pengajaran, alat dan sumber belajar, teknik dan acara penilian, kondisi guru dan kegiatan mengajarnya. Upaya peningkatan prestasi belajar siswa tidak terlepas dari berbagai faktor diantaranya guru harus kreatif dalam merancang proses pembelajaran sehingga pembelajaran menjadi lebih menarik dan disukai oleh peserta didik. Guru harus mampu memberikan kebebasan berfikir kepada siswa dan mampu mengundang mereka untuk menjawab permasalahan melalui berbagai cara.

Atas permasalahan dan penyebab terjadinya permasalahan inilah penulis mencoba menerapkan suatu model pembelajaran yaitu model pembelajaran Kooperatif Tipe Scramble. Hal ini diperkuat dengan belum pernahnya model pembelajaran Kooperatif Tipe Scramble dilaksanakan dalam pembelajaran matematika di SMK Cendana Padangpanjang. Model pembelajaran yang pernah di terapkan guru dari observasi dan wawancara yang telah dilakukan diantaranya adalah metode ceramah, diskusi dan tanda jawab, dan masih kurangnya inovasi guru dalam pemakaian media pembealajaran yang belum ada diterapkan di SMK cendana khususnya kelas XI SMK Cendana Padangpanjang.

Media pembelajaran adalah salah satu upaya dalam peningkatan prestasi belajar siswa. Media pembelajaran termasuk alat bantu dalam proses pembelajaran, didalam model pembelajaran kooperatif tipe scramble ini adalah model pembelajaran menggunakan media kartu berupa kartu jawaban dan kartu jawaban yang diacak susunanya.

Kooperatif tipe scramble adalah suatu model belajar yang menggunakan media kartu soal dan kartu jawaban yang dipasangkan atau diurutkan menjadi urutan logis. Siswa dituntut berpikir kreatif dalam pembelajaran di kelas, untuk mengurutkan kata-kata dalam kunci jawaban menjadi kata yang logis.

Berdasarkan latar belakang pemikiran di atas maka penulis akan melakukan penelitian mengenai Efektivitas Model Pembelajaran Kooperatif Tipe Scramble Dalam Pembelajaran Matematika Dikelas XI SMK Cendana Padang Panjang.

\section{RESEARCH METHODS}

Penelitian ini menggunakan satu kelas sampel yaitu kelas eksperimen yang diberikan perlakuan penerapan model pembelajaran Kooperatif tipe Scramble.

Adapun rancangan penelitian yang digunakan adalah One Group Pretest-Posttest Design.

Populasi pada penelitian ini adalah seluruh siswa kelas XI Cendana Padang Panjang tahun ajaran 2017/2018 yang terdiri dari 2 kelas

Pada penelitian ini sampel yang digunakan sesuai dengan masalah yang akan diteliti dan metode penelitian yang akan digunakan, maka dibutuhkan satu kelas sampel yaitu kelas eksperimen.

Berdasarkan uji normalitas dan uji homogenitas populasi maka diperoleh populasi normal dan homogen, maka teknik pengambilan sampel yang peneliti lakukan adalah secara acak (Random Sampling). Setelah dilakukan pengundian ternyata yang terambil pertama kelas XI TKJ I sebagai kelas eksperimen

Variabel dalam penelitian ini adalah pembelajaran dengan model pembelajaran kooperatif tipe scramble.

a. $T_{1}=$ hasil belajar (pretest) matematika siswa pada ranah kognitif sebelum diberikan perlakuan menggunakan model pembelajaran kooperatif tipe scramble.

b. $T_{2}=$ hasil belajar (posttest) matematika siswa pada ranah kognitif setelah diberikan perlakuan menggunakan model pembelajaran kooperatif tipe scramble.

Data primer dalam penelitian ini adalah hasil belajar matematika siswa pada ranah kognitif. 
Data sekunder dalam penelitian ini adalah jumlah siswa yang menjadi populasi dan nilai Ujian harian 1 kelas XI SMK Cendana Padangpanjang. Data primer diperoleh dari siswa kelas XI SMK Cendana Padangpanjang. Data sekunder diperoleh dari tata usaha dan guru Matematika kelas XI SMK Cendana Padangpanjang.

Instrumen yang digunakan dalam penelitian ini adalah tes hasil belajar yang merupakan salah satu jenis tes yang digunakan untuk mengukur perkembangan atau kemajuan belajar peserta didik, setelah mereka mengikuti proses pembelajaran. Instrumen yang digunakan dalam penelitian ini adalah Tes hasil belajar yang diberikan dalam penelitan ini adalah tes essay. Soal-soal yang diberikan dalam tes ini disesuaikan dengan pokok bahasan yang diberikan selama perlakuan berlangsung. Untuk mendapatkan soal yang baik yaitu valid dan reliabel, maka dilakukan hal-hal sebagai berikut :

a. Membuat kisi-kisi soal pretest-posttest.

b. Menyusun soal pretest-posttest sesuai dengan kisi-kisi soal.

c. Uji coba soal pretest-posttest

d. Melakukan analisis soal
1) Validitas tes
2) Daya pembeda soal
3) Indeks kesukaran soal
4) Klasifikasi Soal
5) Reliabilitas Tes

e. Membuat kisi-kisi soal untuk tes akhir

f. Menyusun soal untuk tes akhir

Analisis data bertujuan untuk menguji hipotesis penelitian, uji hipotesis dalam penelitian ini berguna untuk melihat apakah terdapat efektivitas perlakuan yang diberikan yaitu metode pembelajaran koperatif Tipe scramble terhadap peningkatan hasil belajar matematika siswa.

a. Uji Normalitas

Uji yang digunakan adalah uji Liliefors seperti yang dikemukakan oleh Sudjana (2005 : 466) Berdasarkan hasil analisis uji normalitas untuk nilai pretest dan posttest maka diperoleh bahwa $\mathrm{L}_{0}<\mathrm{L}_{\text {tabel }}$ yang berarti bahwa Hipotesis nol diterima.

b. Uji hipotesis

Langkah - langkah perhitungan :

a) Menentukan SS yaitu Jumlah Kuadrat Simpangan Baku b) Menentukan $s_{d}$ yaitu Simpangan Baku Sampel

c) Menentukan $s_{\bar{D}}$ yaitu Standar Error

d) Menentukan $\bar{D}$ yaitu Rata-Rata Selisih Nilai Pretest dan Nilai Posttest

e) Menentukan $t$ yaitu Penerimaan atau Penolakan Hipotesis

$$
\begin{aligned}
& t=\frac{\bar{D}-\mu_{0}}{S_{\bar{D}}} \quad \text { Dimana } \bar{D}=\frac{\sum D}{n} \\
& S S=\sum D^{2}-\frac{\left(\sum D\right)^{2}}{n} \text { dimana } \\
& S_{d}=\sqrt{\frac{S S}{n-1}} \quad S \bar{D}=\frac{S_{d}}{n}
\end{aligned}
$$

Untuk $\mathrm{t}$ hitung berada diluar daerah penerimaan hipotesis nol maka kita menolak hipotesis nol. Hal ini berarti terdapat efektivitas perlakuan yang diberikan yaitu metode pembelajaran koperatif Tipe scramble terhadap peningkatan hasil belajar matematika siswa..

Secara umum prosedur penelitian dapat dibagi atas tiga bagian, yaitu: tahap persiapan, tahap pelaksanaan, dan tahap akhir.

1. Tahap Persiapan

Hal-hal yang dilakukan dalam tahap persiapan ini adalah sebagai berikut:

a. Menetapkan materi dan tempat penelitian.

b. Menetapkan populasi dan sampel penelitian.

c. Menetapkan rencana jadwal penelitian yang akan dilaksanakan.

d. Mempersiapkan observer.

Observer bertugas mengamati dan mengisi lembar observasi aktifitas guru dan siswa. Observer diberikan pemahaman tentang model pembelajaran koperatif Tipe scramble dan cara penggunaan lembar observasi.

e. Mempersiapkan Perangkat Pembelajaran.

f. Memvalidasi Perangkat Pembelajaran. Sebelum perangkat pembelajaran digunakan untuk penelitian, instrumen tersebut harus divalidasi terlebih dahulu. Adapun perangkat pembelajaran yang divalidasi adalah Rencana Pelaksanaan Pembelajaran (RPP) dan tes hasil belajar

g. Membuat kisi-kisi tes hasil belajar.

h. Mempersiapkan soal tes hasil belajar yang akan diuji coba. 
i. Melakukan uji coba tes.

j. Analisis tes uji coba

$\mathrm{k}$. Menyusun soal pretest-posttest.

2. Tahap pelaksanaan

Adapun hal yang dilakukan pada tahap pelaksanaan adalah :

a. Melakukan pretest sebelum diberikan perlakuan pada kelas eksperimen

b. Melaksanakan pembelajaran dengan model pembelajaran koperatif Tipe scramble

c. Melaksanakan observasi aktifitas guru dan siswa dan psikomotor ketika menerapkan model pembelajaran koperatif Tipe scramble yang dilakukan oleh observer

d. Melakukan posttest

3. Tahap akhir

Tahap akhir dalam penelitian ini meliputi sebagai berikut :

a. Pengumpulan data.

b. Pengelompokan data.

c. Melakukan pengolahan data.

d. Menarik kesimpulan.

e. Penulisan hasil penelitian yang telah dilakukan.

Meliputi analisis, arsitektur dan metode yang dipakai untuk menyelesaikan permasalahan.

\section{RESULTS AND DISCUSSION}

Pada penelitian ini, hasil belajar matematika siswa didapatkan melalui tes. Tes dilaksanakan dua kali yaitu sebelum dan sesudah pembelajaran diberikan, setelah pembelajaran diberikan dengan KKM 75. Pretest dan posttest memiliki soal yang sama yaitu berbentuk uraian sebanyak 10 butir dengan alokasi waktu 90 menit. Pretest pada kelas penelitian diikuti oleh 20 siswa dari 23 siswa sedangkan postest diikuti sebanyak 20 siswa dari 23 siswa.

Antara nilai pretest dan postest terdapat perbedaan rata-rata hasil belajar, dimana hasil belajar kelas postest lebih tinggi dibandingkan hasil pretest baik dilihat dari nilai tertinggi dan nilai terendah.

Pada penelitian ini data yang ambil untuk diolah hanya 20 orang siswa saja karena peneliti hanya mengambil nilai siswa yang mengikuti pretest dan posttest, data yang dianalisis menggunakan statistik inferensial. Untuk data hasil belajar yang diberikan pada kelas sampel dapat dilihat pada table 1 .

Tabel 1

Analisis Data Hasil Belajar Matematika Siswa

\begin{tabular}{|c|c|c|c|c|}
\hline \multirow{2}{*}{ Jenis tes } & \multirow{2}{*}{$\begin{array}{c}\text { Jumlah } \\
\text { peserta }\end{array}$} & $\begin{array}{c}\text { Nilai rata- } \\
\text { rata }\end{array}$ & \multicolumn{2}{|c|}{ Persentase } \\
\cline { 4 - 5 } & & Tuntas & $\begin{array}{c}\text { Tidak } \\
\text { tuntas }\end{array}$ \\
\hline Prest & $\begin{array}{c}20 \\
\text { orang }\end{array}$ & 22,08 & $0 \%$ & $100 \%$ \\
\hline & $\begin{array}{c}20 \\
\text { orang }\end{array}$ & 77,95 & $75 \%$ & $25 \%$ \\
\hline
\end{tabular}

Pada tabel 4.1 terlihat bahwa rata-rata nilai siswa pada saat posttest lebih tinggi dari pada pretest. Selain itu, dapat dilihat bahwa pada saat posttest persentase siswa yang tuntas sesuai KKM sudah mencapai $75 \%$ sedangkan pada pretest $0 \%$ tuntas. Kita dapat melihat bahwa persentase siswa yang mengalami peningkatan nilai pretest sebanyak $75 \%$.

Uji hipotesis pada penelitian ini berguna untuk melihat apakah penerapan model pembelajaran Kooperatif Tipe Scramble efektif peningkatan terhadap hasil belajar matematika siswa di kelas XI SMK Negeri Padangpanjang Tahun Ajaran 2017/ 2018.

Berdasarkan analisis dengan taraf kepercayaan 95\% dan penigkatan sebesar 52 poin diperoleh harga $t_{\text {hitung }}=6,99>1.71=t_{(0,05 ; 20)}$ maka $H_{0}$ ditolak dan $H_{1}$ diterima. Hal ini berarti Terdapat efek peningkatan yang signifikan pada pembelajaran matematika setelah menerapkan model pembelajaran Kooperatif Tipe Scramble, dan sesuai dengan kiteria efektifitas pembelajaran dikatakan efektif apabila sekurang - kurangya telah memenuhi $75 \%$.

Berdasarkan deskriptif data hasil belajar siswa dapat diketahui bahwa hasil belajar siswa saat tes akhir (posttest) lebih tinggi dari pada hasil belajar siswa saat tes awal (pretest). Ini terlihat dari nilai rata-rata pretest yang lebih rendah dari nilai rata-rata posttest, yaitu rata-rata pretest adalah 22,08 sedangkan rata-rata posttest adalah 77,95. Peningkatan nilai rata-rata pretest

Jurnal JIPS (Jurnal Ilmiah Pendidikan Scholastic ) Vol. 3 No. 3 (2019) ISSN : 2579-5449

This work is licensed under a Creative Commons Attribution-NonCommercial 4.0 International License. 
ke posttest adalah 55,89. Berdasarkan KKM yang telah ditetapkan yaitu 75 , dan berdasarkan ciri - ciri efektifitas hasil belajar dikatakan efektif apabila ada peningkatan sebesar $75 \%$, dari rata - rata pretes ke post test, dari 20 anak yang mengikuti post test terdapat 15 anak yang tuntas dan 5 tidak tuntas. Saat pretest $0 \%$ siswa yang mencapai KKM, tapi saat posttest ketuntasan siswa sudah mencapai $75 \%$. Sesuai dengan hipotesis yang telah dikemukakan yaitu terjadi peningkatan nilai pretest sebanyak 52 poin. Hal ini menunjukkan keefektivan model pembelajaran Kooperatif Tipe Scramble untuk meningkatkan hasil belajar siswa dikelas XI SMK Cendana Padangpanjang. Hal ini dibuktikan dari hasil analisis data yaitu dengan menggunakan uji- $t$ diketahui bahwa $t_{\text {hitung }}=$ $6,99>1.71=t_{(0,05 ; 20)}$.

Pada penelitian ini ada beberapa kendala yang peneliti temukan, hal ini terjadi karena peneliti belum memiliki pengalaman yang cukup dalam mengajar.

Adapun kendala yang peneliti temukan antara lain :

1. Sulitnya pengelolaan kelas karena ada beberapa orang siswa yang kurang serius mengikuti pembelajaran. Peneliti mencoba

\section{CONCLUSION}

Berdasarkan hasil penelitian dapat diambil kesimpulan bahwa Hasil belajar matematika pada ranah kognitif siswa yang menggunakan model pembelajaran kooperatif tipe scramble efektif untuk meningkatkan hasil belajar matematika pada siswa kelas XI SMK Cendana Padangpanjang Tahun Pelajaran 2017/2018.

Berdasarkan hasil penelitian yang diperoleh, maka peneliti dapat mengemukakan saran-saran sebagai berikut :

1. Diharapkan guru bidang studi matematika mampu menerapkan pembelajaran matematika dengan model pembelajaran Kooperatif Tipe Scramble karena dapat meningkatkan hasil belajar matematika siswa.

2. Sebaiknya guru dapat menerapkan pembelajaran dengan menerapkan penerapan Penerapan Kooperatif Tipe Scramble, agar para siswa dapat berperan aktif. mengatasi masalah ini dengan mendekati siswa tersebut, memberikan nasihat dan motivasi juga menyuruh siswa tersebut menjelaskan kembali materi yang baru saja dipelajari. Namun cara ini masih kurang efektif.

2. Salah satu RPP yang disiapkan kurang berjalan dengan lancar karena pelajaran berada pada jam terakhir dan istirahat, banyak siswa yang tidak semangat untuk mengikuti pelajaran sehingga kesiapan siswa untuk belajar yang kurang optimal.

3. Kesulitan dalam membimbing dan mengawasi siswa dalam kegiatan kelompok karena siswa tidak pernah menggunakan kegiatan belajar kelompok. Peneliti mencoba mengatasi masalah ini dengan berusaha menegur siswa yang ribut dan memberi batas waktu sehingga siswa tidak punya banyak waktu untuk berbicara dengan temannya.

peneliti sulit membedakan apakah siswa tidak mau bertanya karena sudah paham atau siswa merasa takut dan malu untuk bertanya. Oleh sebab itu, peneliti berinisiatif untuk pergi ke kelompok-kelompok belajar dan menginstruksikan apakah siswa ada kendala atau tidak.

3. Penerapan Kooperatif Tipe Scramble pada penelitian ini diterapkan pada materi fungsi kuadrat,komposisi dan invers oleh karena itu peneliti menyarankan agar penerapan Kooperatif Tipe Scramble pada materi lain dalam pembelajaran matematika dapat diteliti lebih lanjut.

Penulis menyadari bahwa penelitian ini masih jauh dari kesempurnaan karena masih adanya faktor-faktor yang belum diperhatikan secara seksama. Oleh sebab itu, bagi semua pihak yang berkompeten diharapkan untuk dapat mengembangkan penelitian ini, baik sebagai penelitian lanjutan maupun penelitian lain dari model pembelajaran Kooperatif Tipe Scramble, sehingga model pembelajaran baru tersebut dapat berkembang pada dunia pendidikan di negara Indonesia ini. 


\section{Bibliography}

[1]Arifin, Zainal 2009. Evaluasi Pembelajaran. Bandung: Remaja Rosdakarya.

[2]Arikunto, Suharsimi. (2003). Dasar-Dasar Evaluasi Pendidikan. Jakarta: Bumi Aksara. (2007). Dasar-Dasar Evaluasi Pendidikan. Jakarta: Bumi Aksara. (2006). Prosedur Penelitian Suatu Pendekatan Praktik. Jakarta: PT Rineka Cipta

[3]Badan Pengembangan Akademik Universitas Islam Indonesia. (2009)

[4]Daryanto. 2005. Evaluasi Pendidikan. Jakarta: PT Rineka Cipta.

[5]Depdiknas. 2006. Kurikulum Tingkat Satuan Pendidikan (KTSP). Jakarta: Dirjen Dikmenum

[6]Huda, Miftahul. (2014). Model-Model PengajarandanPembelajaran. Yogyakarta: PustakaPelajar.

[7]Hudoyo,Herman.(2001). Pengembangan Kurikulum dan Pembelajaran Matematika. Malang: Universitas Negeri Malang

[8]Ibrahim, Muslim. (2000).Pembelajaran Kooperatif. Surabaya: UNESA.

[9]Lie, Anita. (2002). Cooperative Learning MempraktekanCooperatif Learning di Ruang-RuangKelas. Jakarta: Grasindo

[10]Prawironegoro, Pratikno. 1985. Evaluasi Hasil Belajar Khusus Analisis Soal Bidang StudiMatematika Jakarta: P2LPTK.

[11]Sardiman, A.M. (2001). Interaksi dan Motivasi dalam Belajar Mengajar. Jakarta: Gramedia Widiasarana Indonesia.

[12]Silberman, Melvin L. (2006).Active Lerning 101 Cara Belajar Siswa Aktif.Bandung : Nusamedia.

[13]Siregar, Syofian. (2010). Statistika Deskriptif Untuk Hasil Penelitian
Dilengkapi Perhitungan Manual Dan Aplikasi . Jakarta : Rajawali

[14]Soepono, Bambang. (2002). Statistik Terapan ( Dalam Penelitian Ilmu Ilmu Sosial dan Pendidikan). Jakarta : Rineka Cipta

[15]Sudijono, Anas. (2009). PengantarEvaluasiPendidikan. Jakarta: PT.RajaGrafindoPersada

[16]Sudjana, Nana. (1989). Penilaian Hasil Proses Belajar Mengajar. Bandung: PT Remaja Rosda Karya

[17]Sudjana, Nana. 2001. Penilaian Hasil Proses Belajar mengajar. Bandung: PT Remaja Rosdakarya

[18]Sudjana, Nana. 2013. Penilaian Hasil Proses Belajar Mengajar. Bandung: Remaja Rosdakarya

[19]Sudjana(2005).Metoda Statistika. Bandung : Tarsito.

[20]Sugiyanto. (2009). Model-Model Pembelajaran Inovatif. Surakarta : Panitia Sertifikasi Guru Rayon 13 FKIP UNS Surakarta

[21]Suherman, Erman. (2003). Strategi Pembelajaran Matematika Kontemporer. Bandung : UPI.

[22]Suryabrata, Sumadi. 2011. Metedologi Penelitian. Jakarta : PT Raja Grafindo Persada.

[23]Taufik, Taufina. 2012. Mozaik Pembelajaran Inovatif. Padang : Sukabina Press.

[24]Usmadi, dan Ergusni. (2011). Buku Pedoman Penulisan dan Ujian Skripsi. Padangpanjang: $\quad$ FKIP UMSB Padangpanjang

[25]Winkel, W.S. (2004). PsikologiPengajaranEdisiRevisi.Yogyakar ta :Media Abadi. 